\title{
STK39 variation predicts the ambulatory blood pressure response to losartan in hypertensive men
}

\author{
Kati M Donner, Timo P Hiltunen, Tuula Hannila-Handelberg, Timo Suonsyrjä and Kimmo Kontula
}

Large-scale genome-wide association studies (GWASs) have identified significant associations of common genetic variants with blood pressure (BP) levels. To obtain more evidence for the role of these variants in BP regulation, we studied their association with BP responses to four different antihypertensive drug monotherapies. We selected 19 single-nucleotide variants based on data from five GWASs. The study group consisted of more than 200 hypertensive Finnish men from the GENRES study. Ambulatory BP responses to 4-week treatments with losartan, bisoprolol, hydrochlorothiazide and amlodipine were the primary targets of the study. Secondarily, baseline indicators of the activity of the renin-angiotensin-aldosterone system were studied. After correction for multiple comparisons, the variant rs6749447 in the STK39 gene was significantly associated with BP responses. Thus, the minor rs 6749447 allele was associated with a lower systolic and diastolic BP response to losartan $(P=0.0005$ and 0.0002 , respectively). rs6749447 minor allele homozygotes had marginally higher serum aldosterone/plasma renin activity (PRA) ratios $(P=0.04)$ than those without this allele. In a replication study on aldosterone and renin levels, another cohort of hypertensive patients $(n=311)$ showed a similar trend. When the two cohorts were combined, the aldosterone level $(P=0.02)$ and the aldosterone/PRA ratio $(P=0.01)$ were higher in subjects homozygous for the minor rs6749447 allele than in other subjects. The present study shows that pharmacogenetic approaches may provide evidence that complements systematic genome-wide strategies by identifying gene loci that not only affect the BP level but also might modify its response to pharmacologic interventions.

Hypertension Research (2012) 35, 107-114; doi:10.1038/hr.2011.166; published online 13 October 2011

Keywords: aldosterone; renin; STK39

\section{INTRODUCTION}

Although much effort and various strategies have been used to identify susceptibility genes underlying essential hypertension, ${ }^{1}$ these still remain mostly unidentified. Recently, five large-scale genome-wide association studies (GWASs) have been conducted in an attempt to identify hypertension-susceptibility genes by a systematic approach. ${ }^{2-6}$ Certain progress is supported by the facts that some of these studies have identified concordant chromosomal loci and that additional evidence has been obtained by replication and functional studies. ${ }^{3,4,6-10}$

The increased risk of cardiovascular morbidity and mortality brought up by elevated blood pressure (BP) can be alleviated by effective antihypertensive drug therapy. ${ }^{11}$ However, only one-third of hypertensive patients on antihypertensive medication are adequately controlled for their hypertension. ${ }^{12}$ It is difficult to predict the response to a particular drug in a given patient. Much hope has been put on the use of genetic variants predicting antihypertensive drug responsiveness, but until now, no such markers have been shown to be clinically useful in the treatment of patients with essential hypertension.

The present study was conducted to determine the impact of 19 single-nucleotide variants on ambulatory BP responses to losartan, bisoprolol, hydrochlorothiazide and amlodipine in men with essential hypertension. The variants were selected based on their association with systolic BP (SBP), diastolic BP (DBP) or hypertension in five recent large GWASs. ${ }^{2-6}$ In addition to BP response, the relation of these polymorphisms to baseline characteristics, reflecting the activity of the renin-angiotensin-aldosterone system (RAAS), was also studied. As a platform, we used our unique GENRES study (a study on molecular GENetics of drug RESponsiveness in essential hypertension), which compares the antihypertensive effects of four different drug monotherapies in hypertensive men by using a double-blind crossover design. ${ }^{13}$

\section{METHODS}

Subjects

The GENRES study. The design of the GENRES study has been described in detail. ${ }^{13}$ Briefly, 313 moderately hypertensive Finnish men, aged 35-60 years, were studied. The inclusion criteria were DBP $\geqslant 95 \mathrm{~mm} \mathrm{Hg}$ in repeated measurements or use of antihypertensive medication. Exclusion criteria included use of three or more antihypertensive drugs, secondary hypertension or significant additional morbidity. Of the 244 patients included, 197 were on antihypertensive medication before the study. ${ }^{13}$ Earlier antihypertensive medication was stopped before the study. 
Each patient received losartan $50 \mathrm{mg}$, bisoprolol $5 \mathrm{mg}$, hydrochlorothiazide $25 \mathrm{mg}$ and amlodipine $5 \mathrm{mg}$ daily, each as monotherapy, in a randomized order for 4 weeks. The study started with a 4 -week run-in placebo period, and all four drug treatment periods were separated by 4 -week placebo periods. ${ }^{13}$ A flowchart indicating the numbers of patients screened, included and excluded with respective reasons during the GENRES study is shown in Supplementary Figure S1. For the 24-h ambulatory BP measurements conducted at the end of each drug period, BP levels were recorded every 15 (standing position) or 30 (recumbent position) minutes using a Diasys Integra device (Novacor, Rueil-Malmaison, France). Ambulatory BP levels were calculated as the mean of daytime (0700-2200 hours) and nighttime (2200-0700 hours) values, weighed according to daytime and nighttime hours. ${ }^{13}$ Ambulatory BP recordings were available for 204 subjects during losartan therapy, 208 subjects during bisoprolol therapy, 207 subjects during hydrochlorothiazide therapy and 206 subjects during amlodipine therapy. During the placebo periods, the mean office and ambulatory SBP and DBP levels were $153 / 100$ and $135 / 93 \mathrm{~mm} \mathrm{Hg}$, respectively. Baseline laboratory values were obtained from fasting blood samples at the end of the first placebo period for all subjects. ${ }^{13}$ Plasma renin activity (PRA) and serum aldosterone levels were determined by radioimmunoassay (DiaSorin, Saluggia, Italy). ${ }^{14}$

Replication study of circulating aldosterone and renin levels in referred hypertensive patients. The recruitment and characteristics of referred hypertensive patients have been described previously. ${ }^{15}$ In brief, patients referred to the Hypertension Outpatient Ward of Helsinki University Central Hospital because of hypertension resistant to drug treatment were studied. Secondary hypertension was excluded with appropriate clinical and laboratory examinations. This resulted in a group of 347 patients with essential hypertension, of whom 315 had no medications interfering with serum aldosterone and plasma renin measurements. The required intermission times were 4 weeks for estrogen and spironolactone; 2 weeks for diuretics and prostaglandin inhibitors; and 1 week for $\beta$-blockers and angiotensin-converting enzyme inhibitors. The use of calcium channel blockers and oral potassium supplements was permitted.

The studies were approved by the Ethical Committee of Helsinki University Central Hospital. All subjects signed an informed consent form.

\section{Genotype analysis}

Genomic DNA was extracted from peripheral venous blood according to standard procedures. Based on the available information from GWASs, ${ }^{2-6}$ a total of 19 single-nucleotide variants were selected for the study (Table 1). As three variants, rs1004467 (in 10q24), rs3184504 (in 12q24) and rs2681472 (in 12q21), from the CHARGE study ${ }^{3}$ were in linkage disequilibrium with rs11191548, rs653178 and rs2681492, respectively, in the Global BPgen study ${ }^{4}$ in the HapMap CEU cohort (http://hapmap.ncbi.nlm.nih.gov/index.html.en), only the latter three were included in this study. Two variants, rs35929607 and rs6749447, from a cluster of variants in STK39 were selected because they have been associated with altered gene expression ${ }^{6,8}$ and are located in different linkage disequilibrium bins of the gene. ${ }^{6}$ Genotyping was performed by PCR amplification of the DNA region containing the variant of interest, followed by restriction enzyme digestion and polyacrylamide gel electrophoresis, or by PCR and sequencing. Publicly available databases (http://www.ensembl.org/ index.html and http://snp.cshl.org/) were used to map genomic variations in the area when the primers and the restrictions were designed to ensure the quality of the genotyping. For variants genotyped by primer-introduced restriction analysis-PCR assay, ${ }^{16}$ a publicly available website (http://cedar. genetics.soton.ac.uk/public_html/primer2.html) was used to design oligonucleotides. The genotyping was performed by laboratory personnel blinded to the clinical information. The oligonucleotide sequences, restriction enzymes used, and PCR product and restriction fragment sizes are listed in Supplementary Table S1. For each variant genotyped by PCR and restriction enzyme digestion, 4-10 samples were sequenced to confirm the quality of the genotyping. No discrepancies were detected.

\section{Statistical analysis}

Data were analyzed by using the statistical SPSS program (version 17.0; SPSS Inc., Chicago, IL, USA). The primary targets of the study were ambulatory BP responses to the four antihypertensive drug monotherapies. Secondarily, baseline indicators of RAAS activity, that is, serum aldosterone levels, PRA, and serum sodium and potassium concentrations, were studied. Possible genotyperelated differences in baseline characteristics (BP levels during placebo periods, age, body mass index (BMI) and daily urinary sodium excretion) were also analyzed by Kruskal-Wallis test.

Table 1 Minor allele frequencies (MAF), chromosomal loci, and position of the studied variants and reported MAF and BP effects from the GWASs

\begin{tabular}{|c|c|c|c|c|c|c|c|c|}
\hline & $d b S N P I D$ & Locus & SNP position & $\begin{array}{l}\text { Major/minor allele } \\
\text { in GENRES }\end{array}$ & $\begin{array}{l}\text { MAF in } \\
\text { GENRES }\end{array}$ & Reference & $\begin{array}{c}\text { Reported allele } \\
\text { frequencies }\end{array}$ & $\begin{array}{l}\text { Reported } \\
\text { BP effect }\end{array}$ \\
\hline 1 & rs17367504 & 1 p36 & MTHFR, intron & $A / G$ & 0.15 & Newton-Cheh ${ }^{4}$ & G: $0.14-0.16$ & $A>G$ \\
\hline 2 & rs2820037 & $1 q 43$ & ZP4-CHRM3, intergenic & $\mathrm{A} / \mathrm{T}$ & 0.10 & WTCCC $^{2}$ & $\mathrm{~T}: 0.14-0.17$ & $A<T$ \\
\hline 3 & rs35929607 & $2 q 24$ & STK39, intron & $A / G$ & 0.28 & Wang6 & G: 0.10-0.18 & $A<G$ \\
\hline 4 & rs6749447 & $2 q 24$ & STK39, intron & $T / G$ & 0.29 & Wang 6 & G: 0.19-0.29 & $\mathrm{T}<\mathrm{G}$ \\
\hline 5 & rs9815354 & 3p22 & ULK4, intron & $\mathrm{G} / \mathrm{A}$ & 0.24 & Levy $^{3}$ & A: 0.17 & $\mathrm{G}<\mathrm{A}$ \\
\hline 6 & rs16998073 & $4 q 21$ & FGF5, upstream & $\mathrm{A} / \mathrm{T}$ & 0.33 & Newton-Cheh ${ }^{4}$ & T: $0.19-0.29$ & $A<T$ \\
\hline 7 & rs4977950 & 9 p21 & In gene desert & $\mathrm{G} / \mathrm{C}$ & 0.26 & Wang6 & C: 0.13 & Not reported \\
\hline 8 & rs11014166 & $10 p 12$ & CACNB2, intron & $\mathrm{A} / \mathrm{T}$ & 0.28 & Levy $^{3}$ & T: $0.17-0.34$ & $A>T$ \\
\hline 9 & rs1530440 & $10 q 21$ & c10orf107, intron & $\mathrm{C} / \mathrm{T}$ & 0.18 & Newton-Cheh ${ }^{4}$ & T: $0.18-0.19$ & $C>T$ \\
\hline 10 & rs11191548 & $10 q 24$ & CNNM2-NT5C2, intergenic & $\mathrm{T} / \mathrm{C}$ & 0.09 & Newton-Cheh ${ }^{4}$ & C: $0.08-0.09$ & $\mathrm{~T}>\mathrm{C}$ \\
\hline 11 & rs381815 & $11 \mathrm{p} 15$ & PLEKHA7, intron & $\mathrm{C} / \mathrm{T}$ & 0.23 & Levy $^{3}$ & $\mathrm{~T}: 0.26$ & $\mathrm{C}<\mathrm{T}$ \\
\hline 12 & rs2681492 & $12 q 21$ & $A T P 2 B 1$, intron & $\mathrm{T} / \mathrm{C}$ & 0.07 & Levy $^{3}$ & C: $0.19-0.20$ & $\mathrm{~T}>\mathrm{C}$ \\
\hline 13 & rs653178 & $12 q 24$ & ATXN2, intron & $\mathrm{T} / \mathrm{C}$ & 0.43 & Newton-Cheh ${ }^{4}$ & C: $0.46-0.48$ & $\mathrm{~T}<\mathrm{C}$ \\
\hline 14 & rs2384550 & $12 q 24$ & TBX3, downstream & $\mathrm{G} / \mathrm{A}$ & 0.34 & Levy $^{3}$ & A: 0.35 & $G>A$ \\
\hline 15 & rs1378942 & $15 q 24$ & CSK, intron & $\mathrm{A} / \mathrm{C}$ & 0.45 & Newton-Cheh ${ }^{4}$ & C: $0.33-0.36$ & $A<C$ \\
\hline 16 & rs6495122 & $15 q 24$ & $C P L X 3-U L K 3$, intergenic & $\mathrm{A} / \mathrm{C}$ & 0.48 & Levy $^{3}$ & C: 0.58 & $A>C$ \\
\hline 17 & rs1 1646213 & $16 q 23$ & 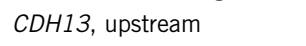 & $\mathrm{T} / \mathrm{A}$ & 0.38 & $\operatorname{Org}^{5}$ & A: $0.34-0.45$ & $\mathrm{~T}>\mathrm{A}$ \\
\hline 18 & rs12946454 & $17 q 21$ & $P L C D 3$, intron & $\mathrm{A} / \mathrm{T}$ & 0.25 & Newton-Cheh ${ }^{4}$ & $\mathrm{~T}: 0.25-0.28$ & $A<T$ \\
\hline 19 & rs16948048 & $17 q 21$ & ZNF652, upstream & $A / G$ & 0.46 & Newton-Cheh ${ }^{4}$ & G: $0.37-0.39$ & $A<G$ \\
\hline
\end{tabular}

Abbreviations: BP, blood pressure; GWAS, genome-wide association study; WTCCC, Wellcome Trust Case Control Consortium. 
Variables were subjected to univariate analysis by using Kruskal-Wallis test. Multivariate analysis with genotypes as nominal categories was performed by using the General Linear Model Univariate procedure, with non-normally distributed variables (age, duration of hypertension, daily urinary sodium excretion, BP levels during placebo periods and creatinine clearance) normalized by Blom's method. For multivariate analysis of BP responses, genotype and earlier antihypertensive medication were used as fixed factors, and age, duration of hypertension, BMI, daily urinary sodium excretion and BP levels during placebo periods were used as covariates.

For multivariate analysis of serum aldosterone levels, PRA, serum sodium concentration and serum potassium concentration, genotype and smoking were used as fixed factors, and age, BMI, daily urinary sodium excretion and creatinine clearance were used as covariates. In addition, in the GENRES study, duration of hypertension was included as a covariate and earlier use of antihypertensive medication was included as a fixed factor. In the replication study of the referred hypertensive patients, sex, examination place (outpatient/ inpatient), use of a calcium channel blocker and use of potassium supplementation were included as fixed factors. In multivariate analysis in the combined GENRES and referred hypertensive patients, the origin (GENRES study subjects or referred hypertensive patients) and the examination place for referred hypertensive patients (outpatient or inpatient) were adjusted for; that is, the examination place consisted of three categories (GENRES/outpatient/ inpatient). Because antihypertensive drug BP responses are related to baseline characteristics such as BP level and age, ${ }^{13}$ the results of multivariate analyses were primarily considered when interpreting the results. As a consistency check, univariate analysis $P$-values are also provided for the most significant findings in the text and for all variants in Supplementary Table S2.

The reported $P$-values are not corrected for multiple comparisons. As 19 genotypes and the highly concordant SBP and DBP responses to four study drugs were included, 76 genotype-related comparisons were performed; thus, a significance level of 0.0007 using the Bonferroni correction was required. Therefore, any association of gene loci with BP responses having $P$-values greater than 0.0007 should only be considered suggestive. Corresponding judgment was applied to the four secondary target variables and the four baseline characteristic variables.

The GENRES study protocol included a priori power calculations. ${ }^{13}$ For the current study, post-hoc calculations were performed by using the $\mathrm{G}^{\star}$ Power 3 program $^{17}$ and the mean observed s.d. of DBP responses $(4.25 \mathrm{~mm} \mathrm{Hg}),{ }^{14}$ allele frequencies 0.50/0.50 (best-case scenario giving genotype group sizes 50-10050) and an $\alpha$-level of 0.0007 . Assuming clinically meaningful DBP response levels of 2, 4 and $6 \mathrm{~mm} \mathrm{Hg}$ for the genotype groups gives a power of $82 \%$. For smaller differences of $1 \mathrm{~mm} \mathrm{Hg}$, the power is $9 \%$.

\section{RESULTS}

\section{Allele frequencies and baseline characteristics}

Successful genotyping calls were obtained for $98.4-100 \%$ of the samples, with an overall success rate of $99.3 \%$. Minor allele frequencies varied between 0.07 and 0.48 (Table 1). All variants, except rs35929607 located in the STK39 gene $(P=0.007)$, were in accordance with HardyWeinberg equilibrium. A total of 48 subjects were genotyped by sequencing to ensure that there were no technical problems in the genotyping of this variant. No discrepancies were observed between genotypes determined by PCR amplification followed by restriction enzyme digestion and genotypes determined by sequencing. Because a total of 19 variants were genotyped, it is possible that this deviation from Hardy-Weinberg equilibrium resulted from a chance occurrence.

Medians, interquartile ranges and Kruskal-Wallis $P$-values for age, BMI, daily urinary sodium excretion, and ambulatory SBP and DBP during placebo treatment for different genotypes are listed in Supplementary Table S2. Compared with subjects from the other genotype groups, subjects homozygous for the major rs653178 allele in the ATXN2 gene had a higher SBP and DBP during placebo treatment ( $P=0.0002$ and 0.007 , respectively), a difference opposite to the original study. ${ }^{4}$ Because both homozygous genotype groups had higher BP levels than the heterozygotes, the significance of this association remains obscure and may represent a chance finding. Other genotype-related differences in baseline characteristics were not significant.

\section{Sequence variants and their relation to antihypertensive drug responses}

The medians, interquartile ranges, Kruskal-Wallis $P$-values and multivariate analysis $P$-values for BP response to amlodipine, bisoprolol, hydrochlorothiazide and losartan for all genotypes are listed in Supplementary Table S2.

The minor allele of rs6749447 of the STK39 locus was associated with a significantly lower SBP and DBP response to losartan $(P=0.004$ and 0.001, in Kruskal-Wallis test, and $P=0.0005$ and 0.0002 , in multivariate analysis, respectively) (Figure 1 and Supplementary Table S2). The median decrease in SBP with losartan treatment was $7.0 \mathrm{~mm} \mathrm{Hg}$ both for subjects who were heterozygous and subjects who were homozygous for the minor allele. The corresponding decrease for subjects who were homozygous for the major allele was $10.8 \mathrm{~mm} \mathrm{Hg}$ (Figure 1). The median decrease in DBP with losartan treatment was $3.4 \mathrm{~mm} \mathrm{Hg}$ for subjects who were homozygous for the minor allele, $4.6 \mathrm{~mm} \mathrm{Hg}$ for subjects who were heterozygous and $6.8 \mathrm{~mm} \mathrm{Hg}$ for subjects who were homozygous for the major allele (Figure 1). The basic multivariate model with no single-nucleotide variant included explained only a small fraction of the total variability of losartan BP response: the adjusted R2 values for SBP/DBP were only 0.024/0.039. Inclusion of the rs6749447 variant in the model increased the adjusted $\mathrm{R} 2$ values to $0.088 / 0.116$.

The associations between the rs6749447 variant and losartan response were the only associations that reached a significant level $(P<0.0007)$. No difference in ambulatory BP responses to losartan was observed between any of the other genotypes studied.

In addition to this association, there were altogether four variants, two for BP response to amlodipine (rs11191548 and rs6749447) and two for BP response to bisoprolol (rs17367504 and rs11014166), that showed some indication $(P<0.05)$ of genotype-related differences to the study drugs (Figure 2 and Table 2). No difference in BP response to hydrochlorothiazide was observed between any of the genotypes studied.
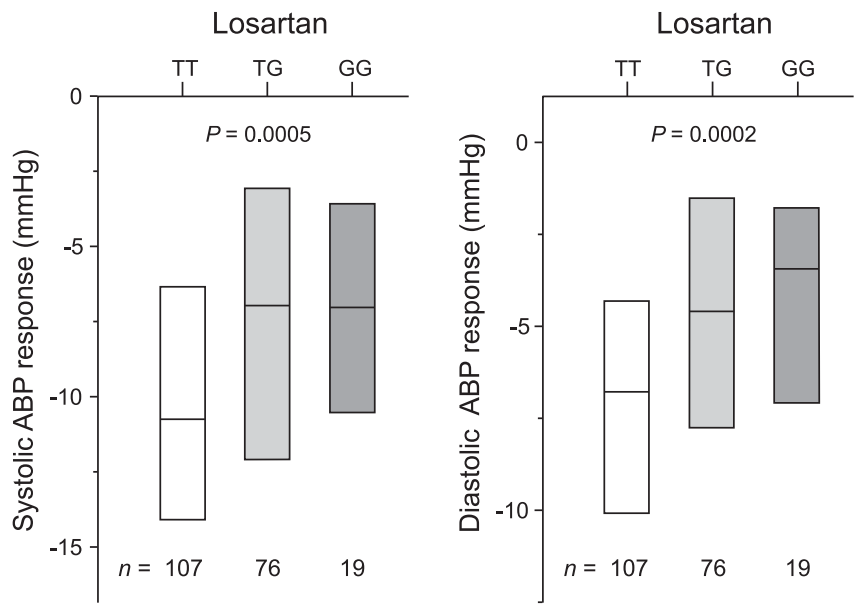

Figure 1 Systolic and diastolic ambulatory BP (ABP) response to losartan in different rs6749447 genotype groups. The boxplots show medians and interquartile ranges. $P$-values from comparison of the different genotype groups in multivariate analysis are shown. 


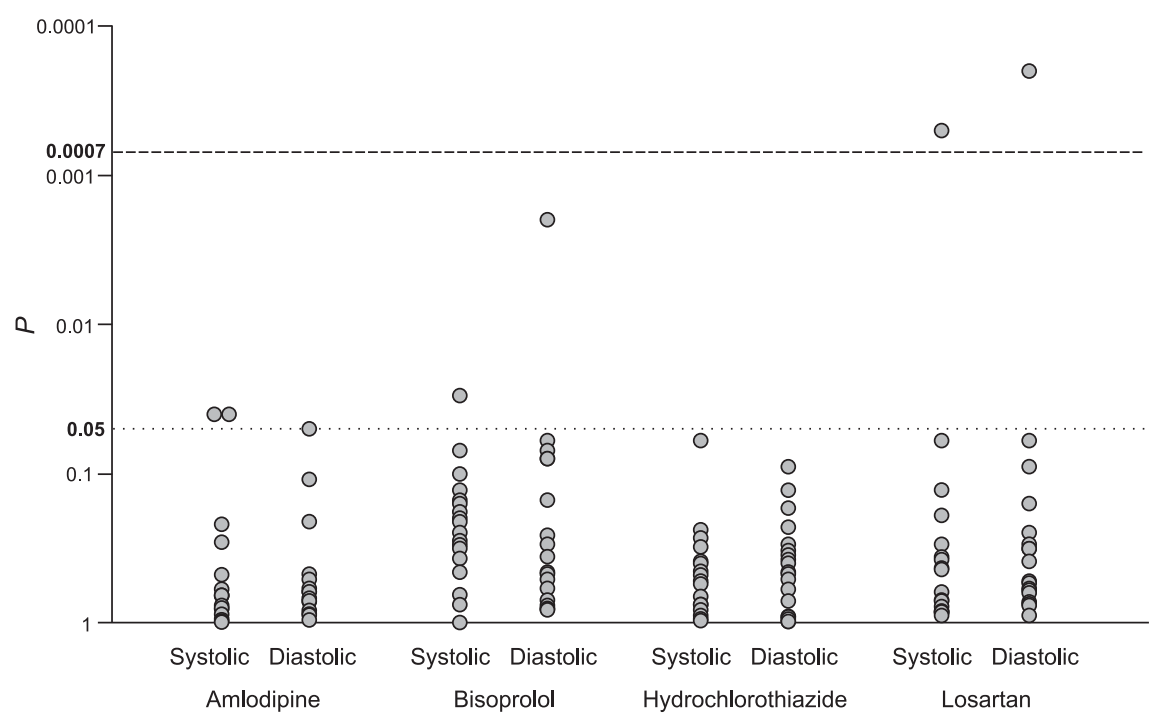

Figure 2 Multivariate analysis $P$-values for systolic and diastolic ambulatory BP (ABP) responses to amlodipine, bisoprolol, hydrochlorothiazide and losartan for the studied variants. The significance level of 0.0007 , applying the Bonferroni correction, is indicated by the broken line and the significance level of 0.05 is indicated by the dotted line.

Table 2 Variants associated with $\boldsymbol{P}<0.0007$ or showing some indication of $(\boldsymbol{P}<0.05)$ genotype-related difference in BP response to GENRES study drugs

\begin{tabular}{|c|c|c|c|c|c|c|c|}
\hline \multirow[t]{2}{*}{$\mathrm{BP}$ response to losartan } & rs6749447 & SBP & 0.0005 & $\mathrm{TT} / \mathrm{TG} / \mathrm{GG}$ & $107 / 76 / 19$ & $10.8 / 7.0 / 7.0$ & $\mathrm{~T}$ \\
\hline & rs6749447 & DBP & 0.0002 & $\mathrm{TT} / \mathrm{TG} / \mathrm{GG}$ & $107 / 76 / 19$ & $6.8 / 4.6 / 3.4$ & $\mathrm{~T}$ \\
\hline $\mathrm{BP}$ response to amlodipine & rs6749447 & SBP & 0.04 & $\mathrm{TT} / \mathrm{TG} / \mathrm{GG}$ & $109 / 76 / 19$ & $7.7 / 6.5 / 8.3$ & $?$ \\
\hline \multirow[t]{2}{*}{ BP response to bisoprolol } & rs17367504 & DBP & 0.002 & $\mathrm{AA} / \mathrm{AG} / \mathrm{GG}$ & $152 / 51 / 3$ & $7.4 / 10.5 / 5.6$ & G \\
\hline & rs11014166 & SBP & 0.03 & $\mathrm{AA} / \mathrm{AT} / \mathrm{TT}$ & $109 / 80 / 17$ & $11.6 / 9.7 / 9.8$ & A \\
\hline
\end{tabular}

Abbreviation: BP, blood pressure.

Median values and interquartile ranges are listed in Supplementary Table S2.

Table 3 Variants showing some indication of $(P<0.05)$ of genotype-related differences in PRA and serum aldosterone levels

\begin{tabular}{lcccccc}
\hline Variable & Variant & P-value & Genotype & Medians & $\mathrm{n}$ & Allele with higher activity or level \\
\hline Plasma renin activity & $\mathrm{rs} 11191548$ & 0.02 & TT/TC/CC & $1.2 / 0.7 / 1.4$ & $203 / 35 / 3$ & T \\
& rs2820037 & 0.03 & AA/AT/TT & $1.0 / 1.2 / 1.9$ & $197 / 42 / 3$ & T \\
Serum aldosterone & rs16998073 & 0.004 & AA/AT/TT & $401 / 484 / 401$ & $111 / 108 / 25$ & $?$ \\
\hline
\end{tabular}

Abbreviations: BP, blood pressure; PRA, plasma renin activity.

Median values and interquartile ranges are listed in Supplementary Table S2.

Sequence variants and PRA, serum aldosterone levels and cation concentrations in the GENRES study

The medians, interquartile ranges, and Kruskal-Wallis and multivariate analysis $P$-values for serum aldosterone levels, PRA, and serum sodium and potassium concentrations for all the genotypes, are listed in Supplementary Table S2.

Three variants, two for PRA (rs2820037 and rs11191548) and one for serum aldosterone levels (rs16998073), showed some indication $(P<0.05)$ of genotype-related differences (Table 3$)$. No differences in serum sodium or potassium concentrations were observed between any of the genotypes studied.
As the rs6749447 variation of the STK39 locus was significantly associated with BP response to losartan, we analyzed its relation to the baseline indicators of RAAS activity more carefully. Slightly lower PRA and higher serum aldosterone levels were observed in subjects with the minor rs6749447 allele ( $P=0.29$ and 0.12 , respectively, in multivariate analysis). Accordingly, we also studied the serum aldosterone/PRA ratio and found that the minor homozygous subjects had a slightly higher ratio than subjects with the major allele $(P=0.04$ in multivariate analysis) (Figure 3a). Inclusion of the aldosterone/PRA ratio to the multivariate model did not affect the association between the rs6749447 variant and BP response to losartan. 
a

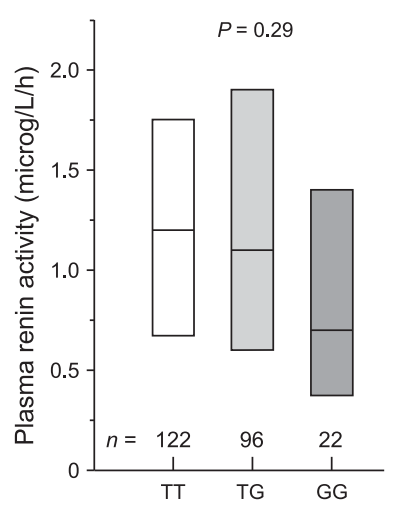

b

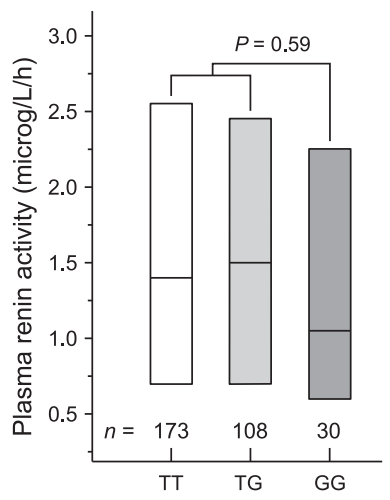

C

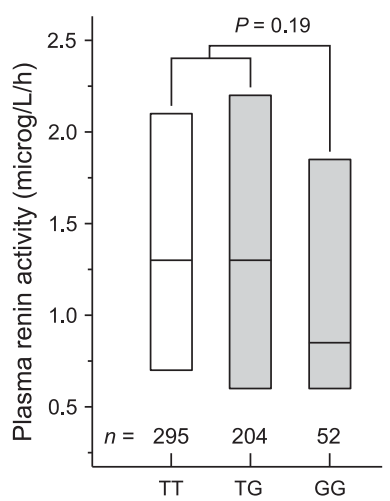

GENRES Study subjects
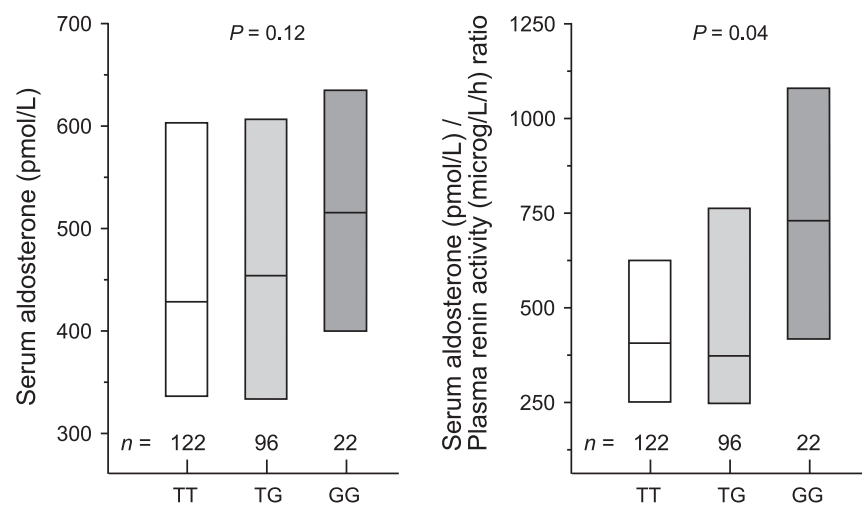

Referred hypertensive patients
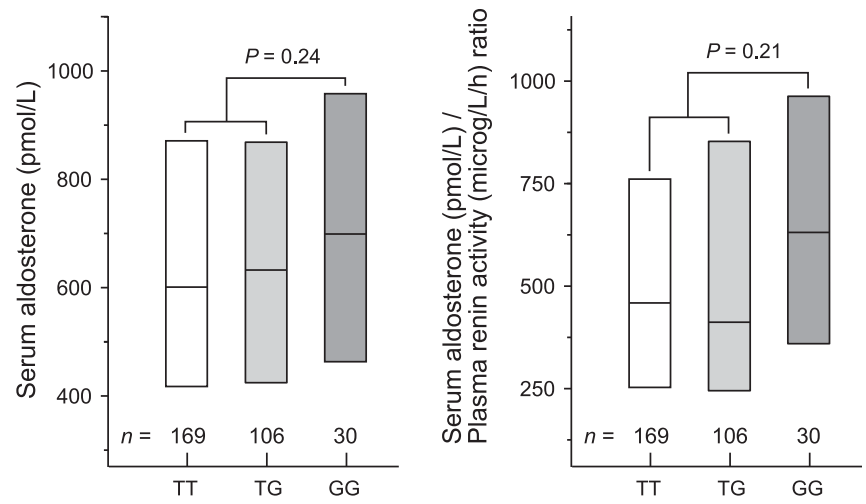

Combined data
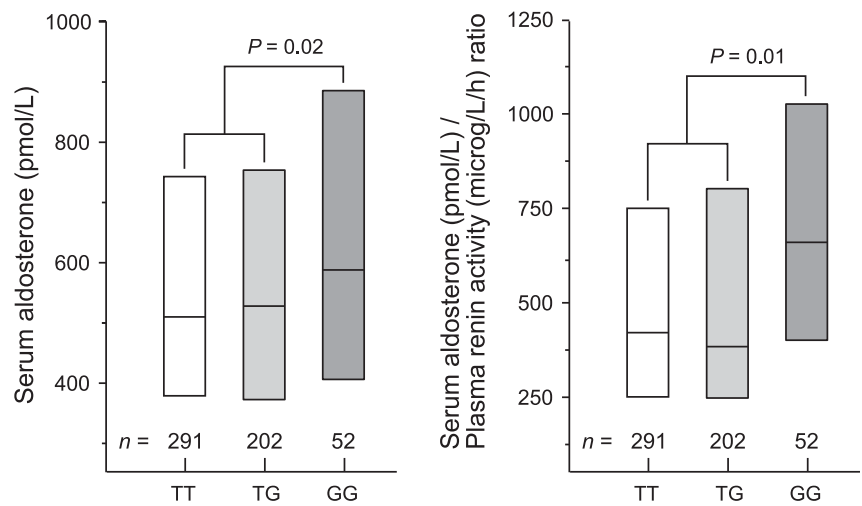

Figure 3 Baseline PRA, serum aldosterone level and serum aldosterone/PRA ratio in different rs6749447 genotype groups in the GENRES study subjects (a), in referred hypertensive patients (b), and in a combined group of GENRES subjects and referred hypertensive patients (c). The boxplots show medians and interquartile ranges. $P$-values from comparison of the different genotype groups in multivariate analysis are shown.

\section{Replication of STK39 rs6749447-related results in referred hypertensive patients}

We performed a replicate analysis on STK39 variation and its relation to blood aldosterone and renin levels in 315 referred hypertensive patients, of whom 311 were successfully genotyped. The genotype distribution was in accordance with Hardy-Weinberg equilibrium and the observed minor allele frequency was 0.27 . No differences in age, BMI, daily urinary sodium excretion, and serum sodium or potassium concentrations were observed between the STK39 genotypes.

Referred hypertensive patients homozygous for the minor rs6749447 allele (genotype GG) tended to have lower PRA, higher aldosterone levels and a consequently higher aldosterone/PRA ratio than patients with the major allele, but the differences between the genotypes were not statistically significant (Figure 3b). When genders were analyzed separately, similar trends for lower PRA, higher aldosterone levels and higher aldosterone/PRA ratios in the GG genotype compared with the other genotypes (median values indicated) were observed in both males (genotypes GG vs. GT+TT: PRA, 0.7 vs. $1.5 \mu \mathrm{gl}^{-1} \mathrm{~h}^{-1}$; aldosterone, 866 vs. $661 \mathrm{pmoll}^{-1}$; and aldosterone/PRA ratio, 858 vs. $\left.446 \mathrm{pmol}_{\mu \mathrm{g}}^{-1} \mathrm{~h}\right)$ and females (genotypes GG vs. GT+TT: PRA, 1.1. vs. $1.4 \mu \mathrm{gl}^{-1} \mathrm{~h}^{-1}$; aldosterone, 622 vs. $565 \mathrm{pmoll}^{-1}$; and aldosterone/PRA ratio, 549 vs. 
$446 \mathrm{pmol} \mu \mathrm{g}^{-1} \mathrm{~h}$ ), although these differences remained statistically non-significant in both sexes.

However, when PRA, aldosterone levels and aldosterone-to-renin ratios were analyzed in relation to the rs6749447 allele in the pooled group of GENRES patients and referred hypertensive patients, PRA was slightly lower (Mann-Whitney GG vs. GT+TT $P=0.05$ and multivariate $P=0.19$ ), and aldosterone levels (Mann-Whitney GG vs. GT+TT $P=0.09$ and multivariate $P=0.02$ ) and aldosterone/PRA ratios were higher (Mann-Whitney GG vs. GT+TT $P=0.002$ and multivariate $P=0.01$ ) in subjects homozygous for the minor allele (Figure 3c). Note that baseline aldosterone levels were somewhat higher in referred hypertensive patients than in the moderately hypertensive GENRES study subjects (Figures $3 \mathrm{a}$ and b). Because elevated BP has been associated with elevated aldosterone levels, ${ }^{18}$ this probably reflects the more severe form of hypertension present in referred hypertensive patients.

\section{DISCUSSION}

We report a pharmacogenetic analysis, directed by available GWAS data, on the relation between 19 postulated susceptibility loci for hypertension and responses to four different varieties of antihypertensive drug treatment. As a principal finding, we obtained evidence indicating that carriers of the STK39 minor rs6749447 allele (G allele) have $3-4 \mathrm{mmHg}$ smaller systolic and diastolic antihypertensive responses to losartan than those without this allele (Figure 1). We also obtained some evidence suggesting that the rs6749447 polymorphism is associated with circulating aldosterone-to-renin ratios in the GENRES study subjects. In a replication study performed in another cohort of hypertensive subjects, a similar trend was observed. When data from these two cohorts were pooled, patients homozygous for the minor rs6749447 allele had significantly higher aldosterone levels and aldosterone-to-renin ratios than subjects with the other rs6749447 genotypes.

In the GENRES study, ${ }^{13}$ the efficacy of four different types of drugs was studied in each individual, thus providing a specificity test to the effect of each class of drug. The use of four different placebo periods between the drug treatments to derive baseline BP levels diminishes statistical variation, and $24-\mathrm{h}$ ambulatory BP recordings were performed throughout the study.

STK39 encodes a serine threonine kinase (STE20/SPS1-related proline/alanine-rich kinase or SPAK) that regulates ion homeostasis and volume control in mammalian cells, by controlling both the activity and the expression of renal cation-chloride co-transporters, including the $\mathrm{Na}^{+}-\mathrm{K}^{+}-2 \mathrm{Cl}^{-}$co-transporter (NKCC1), the thiazidesensitive $\mathrm{Na}^{+}-\mathrm{Cl}^{-}$co-transporter (NCC) and the bumetanide-sensitive $\mathrm{Na}^{+}-\mathrm{K}^{+}-2 \mathrm{Cl}^{-}$co-transporter (NKCC2). ${ }^{19}$ SPAK is one of the kinases proposed to operate under the control of WNK kinases (WNK1, WNK2, WNK3 and WNK4) and to activate the co-transporters by protein phosphorylation. ${ }^{19}$ This closely links the action of SPAK to regulation of the extracellular fluid volume and thereby BP.

Common variation of STK39 was initially associated with office SBP and DBP levels in Amish and non-Amish Caucasian cohorts, totally comprising more than 7000 individuals. ${ }^{6}$ Three recent studies have provided additional evidence for the role of STK39 in hypertension. ${ }^{7,9,10}$ First, a study performed in 1017 African Americans (509 hypertensives and 508 normotensives) was able to provide supporting evidence for the association of STK39 variants and office SBP and DBP levels. ${ }^{7}$ Second, in a study performed with 5808 Han Chinese (2746 hypertensives (1665 males) and 3062 normotensives (2006 males)), two STK39 variants were identified as risk factors for male hypertension. ${ }^{9}$ Third, in a study conducted in two Swedish cohorts consisting of over 20000 participants, the rs35929607 variant in STK39 was associated with hypertension, especially in women $(n>13000) .{ }^{10}$ Some evidence of a role for STK39 variants in salt sensitivity was also obtained from this study when the salt sensitivity was studied in 39 Swedish normotensive subjects ${ }^{10}$ and from a study of 101 Korean subjects (73 salt-resistant and 28 salt-sensitive). ${ }^{20}$ By contrast, the association between three of the STK39 variants (rs3754777, rs35929607 and rs6749447) and ambulatory BP could not be confirmed in a family-based British Caucasian study involving 1372 subjects from 247 families ascertained through probands with essential hypertension, although the same authors were able to provide in vitro data favoring a potential role for STK39 in BP regulation (see below). ${ }^{8}$

Because our studies are focused on BP responses to antihypertensive drugs and RAAS activity, our results cannot confirm the association between STK39 variation and elevated BP. These data do, however, suggest that STK39 variation may influence the phenotype, including drug responsiveness, of hypertension. Additional evidence supporting the role of STK39 variation in BP regulation comes from experimental studies in vitro. Wang et al. ${ }^{6}$ performed transfection experiments using artificial luciferase constructs in HELA and HEK293 cell lines, and were able to demonstrate that the minor G allele of rs35929607, associated with elevated $\mathrm{BP}$, was also associated with enhanced gene transcription. The same authors also investigated the expression pattern of SPAK in rat kidney and found SPAK immunostaining at the sites of NCC and/or NKCC2 expression, including the thick ascending loop of Henle, the distal convoluted tubules and the cortical collecting ducts. ${ }^{6}$ Cunnington et al. ${ }^{8}$ investigated potential STK39 allelic expression differences in peripheral blood, using lymphocyte samples from STK39 heterozygotes and the allelic expression imbalance technique. The most significant association was for rs6749447, with the minor $\mathrm{G}$ allele estimated to have a $13 \%$ increase in expression relative to the major $\mathrm{T}$ allele. ${ }^{8}$ The minor allele was associated with elevated BP in the initial GWAS. ${ }^{6}$ In concordance with the in vitro transfection experiments performed using luciferase constructs, ${ }^{6}$ the corresponding increase in expression for the minor $G$ allele of rs35929607 was estimated to be $7 \% .^{8}$ Collectively, the available GWASs and in vitro data, as well as the fact that no coding or splicing variants were identified in the STK39 region associated with hypertension, ${ }^{6}$ strongly suggest that STK39 variation is indeed associated with risk of hypertension and that the variants identified are functionally relevant.

In our study, the minor $\mathrm{G}$ allele of rs6749447 was associated with a significantly lower ambulatory SBP and DBP response to the angiotensin-II receptor type-1 blocker losartan. This association reached a significant level even after correction for multiple testing. In addition, subjects homozygous for the minor $\mathrm{G}$ allele appear to have a higher serum aldosterone/PRA ratio, as judged by a combined study of two hypertensive patient groups (Figure 3 ). The mechanisms underlying these associations remain poorly understood at present. AngiotensinII increases the activity of the NCC in vitro as studied in Xenopus oocytes. ${ }^{21}$ This activation is mediated by the serine-threonine protein kinases WNK4 and SPAK. ${ }^{21}$ The use of a dominant-negative SPAK, or elimination of SPAK, prevents activation of NCC by angiotensin-II. Activation of NCC requires phosphorylation of regulatory sites of SPAK, which is blocked by losartan. ${ }^{21}$ In accordance with these findings, Talati et al. ${ }^{22}$ recently reported that angiotensin-II phosphorylates and upregulates NCC in cultured mouse kidney cells as well as in mice in vivo. Furthermore, knock-in mouse with STK39 mutations that prevent activation of SPAK by WNK1 and WNK4 have reduced NCC and NKCC2 expression in the kidneys and also reduced BP. ${ }^{23}$ The complexity of this regulatory system is even more increased in 
view of findings showing that aldosterone is directly involved in the phosphorylation of SPAK and NCC, which action is activated by lowsalt diets. ${ }^{24}$

Although STK39 mRNA is known to be expressed in the adrenal cortex (http://biogps.gnf.org/), we can still not provide an explanation for a relation between an STK39 genotype compatible with increased SPAK expression and relative overproduction of aldosterone compared with PRA (Figure 3). Whatever the underlying cause, this endocrine profile may partly explain the relatively limited efficacy of losartan in these individuals. The minor rs6749447 allele has been associated with increased STK39 expression. ${ }^{8}$ In our study, patients with the minor rs6749447 allele did not have a better BP response to hydrochlorothiazide that would block increased NCC activity. A lack of association between STK39 variation and thiazide responsiveness was also very recently reported by Duarte et al. ${ }^{25}$ It is therefore possible that the observed effect of the minor allele of rs6749447 on losartan response is mediated by pathways other than NCC.

There are several important limitations in the present study. Only White men were studied, and even if the GENRES study represents the largest multi-drug pharmacogenomic study on hypertension using a double-blind, cross-over approach and ambulatory BP recordings thus far, its power to find significant associations between gene variants and 1- to 2-mm Hg differences in drug responses is limited. Furthermore, the results of our study may not necessarily be valid for the clinically often encountered situations where angiotensin-II receptor blockers are used as components of drug combinations. In summary, the present study should be considered exploratory in nature, calling for replication studies in which associations between genetic variation and responses to losartan and other angiotensin blockers are studied.

Of all 19 gene variants selected and four drugs examined, the association between BP response to losartan and the rs6749447 variant in the STK39 gene was the only one that reached a significant level. While this association in terms of genotype-related differences in BP responses may at first glance appear only nominal, it should be emphasized that we used a preset hypothesis by selection of a panel of genetic variants with a proposed role in regulation of BP level. We also used a highly conservative statistical approach and were able to replicate the endocrinological results. While our study was designed to study BP responses to specific study drugs in essential hypertension, most of the GWASs were set to detect differences in population-based BP levels or associations to hypertension per se.

The negative results for most of the variants might be explained by the different settings between our study and the GWASs. There were, however, several variants that yielded $P$-values $<0.05$ (but higher than the Bonferroni-corrected level 0.0007) for BP response to the study drugs (Table 2). The significance of these findings remains to be explored. Three variants, one for serum aldosterone levels (rs16998073) and two for PRA (rs2820037 and rs11191548), yielded $P$-values $<0.05$. The lower aldosterone levels observed in subjects homozygous for the minor or the major rs16998073 allele, and the higher PRA observed in subjects homozygous for the minor or the major rs11191548 allele as compared with subjects heterozygous for these alleles, remain obscure. In the case of rs11191548, this might be a chance finding caused by the low number $(n=3)$ of the minor allele homozygotes. Considering these single-nucleotide variants (Table 3), only in the case of the rs2820037 variation PRA followed a logical genetic model, but this association did not reach sufficient significance upon strict statistical analysis.

In conclusion, as a novel finding this study demonstrates an association between the rs6749447 polymorphism of the STK39 gene and $\mathrm{BP}$ responses to losartan. We believe that this finding, supplemented with baseline data suggesting association of the same variation with circulating renin and aldosterone levels, provides further support for STK39 as a susceptibility gene for essential hypertension. If confirmed, these findings may have applicability toward antihypertensive drug design.

\section{CONFLICT OF INTEREST}

The authors declare no conflict of interest.

\section{ACKNOWLEDGEMENTS}

We thank Susanna Saarinen and Hanna Nieminen for excellent technical assistance. The study was supported by grants from The Academy of Finland, The Sigrid Juselius Foundation and the Finnish Foundation for Cardiovascular Research.

1 Cowley Jr AW. The genetic dissection of essential hypertension. Nat Rev Genet 2006; 7: $829-840$.

2 Wellcome Trust Case Control Consortium. Genome-wide association study of 14000 cases of seven common diseases and 3000 shared controls. Nature 2007; 447: 661-678.

3 Levy D, Ehret GB, Rice K, Verwoert GC, Launer LJ, Dehghan A, Glazer NL, Morrison AC, Johnson AD, Aspelund T, Aulchenko Y, Lumley T, Kottgen A, Vasan RS, Rivadeneira F, Eiriksdottir G, Guo X, Arking DE, Mitchell GF, Mattace-Raso FU, Smith AV, Taylor K, Scharpf RB, Hwang SJ, Sijbrands EJ, Bis J, Harris TB, Ganesh SK, O'Donnell CJ, Hofman A, Rotter JI, Coresh J, Benjamin EJ, Uitterlinden AG, Heiss G, Fox CS, Witteman JC, Boerwinkle E, Wang TJ, Gudnason V, Larson MG, Chakravarti A, Psaty BM, van Duijn CM. Genome-wide association study of blood pressure and hypertension. Nat Genet 2009; 41: 677-687.

4 Newton-Cheh C, Johnson T, Gateva V, Tobin MD, Bochud M, Coin L, Najjar SS, Zhao JH, Heath SC, Eyheramendy S, Papadakis K, Voight BF, Scott LJ, Zhang F, Farrall M, Tanaka T, Wallace $C$, Chambers JC, Khaw KT, Nilsson P, van der Harst P, Polidoro S, Grobbee DE, Onland-Moret NC, Bots ML, Wain LV, Elliott KS, Teumer A, Luan J, Lucas G, Kuusisto J, Burton PR, Hadley D, McArdle WL, Brown M, Dominiczak A, Newhouse SJ, Samani NJ, Webster J, Zeggini E, Beckmann JS, Bergmann S, Lim N, Song K, Vollenweider P, Waeber G, Waterworth DM, Yuan X, Groop L, Orho-Melander M, Allione A, Di Gregorio A, Guarrera S, Panico S, Ricceri F, Romanazzi V, Sacerdote C, Vineis P, Barroso I, Sandhu MS, Luben RN, Crawford GJ, Jousilahti P, Perola M, Boehnke M, Bonnycastle LL, Collins FS, Jackson AU, Mohlke KL, Stringham HM, Valle TT, Willer CJ, Bergman RN, Morken MA, Doring A, Gieger C, Illig T, Meitinger T, Org E, Pfeufer A, Wichmann HE, Kathiresan S, Marrugat J, O'Donnell CJ, Schwartz SM, Siscovick DS, Subirana I, Freimer NB, Hartikainen AL, McCarthy MI, O'Reilly PF, Peltonen L, Pouta A, de Jong PE, Snieder H, van Gilst WH, Clarke R, Goel A, Hamsten A, Peden JF, Seedorf U, Syvanen AC, Tognoni G, Lakatta EG, Sanna S, Scheet P, Schlessinger D, Scuteri A, Dorr M, Ernst F, Felix SB, Homuth G, Lorbeer R, Reffelmann T, Rettig R, Volker U, Galan P, Gut IG, Hercberg S, Lathrop GM, Zelenika D, Deloukas P, Soranzo N, Williams FM, Zhai G, Salomaa V, Laakso M, Elosua R, Forouhi NG, Volzke H, Uiterwaal CS, van der Schouw YT, Numans ME, Matullo G, Navis G, Berglund G, Bingham SA, Kooner JS, Connell JM, Bandinelli S, Ferrucci L, Watkins H, Spector TD, Tuomilehto J, Altshuler D, Strachan DP, Laan M, Meneton P, Wareham NJ, Uda M, Jarvelin MR, Mooser V, Melander O, Loos RJ, Elliott P, Abecasis GR, Caulfield M, Munroe PB. Genome-wide association study identifies eight loci associated with blood pressure. Nat Genet 2009; 41: 666-676.

5 Org E, Eyheramendy S, Juhanson P, Gieger C, Lichtner P, Klopp N, Veldre G, Doring A, Viigimaa M, Sober S, Tomberg K, Eckstein G, Kelgo P, Rebane T, Shaw-Hawkins S, Howard P, Onipinla A, Dobson RJ, Newhouse SJ, Brown M, Dominiczak A, Connell J, Samani N, Farrall M, Caulfield MJ, Munroe PB, Illig T, Wichmann HE, Meitinger T, Laan $\mathrm{M}$. Genome-wide scan identifies $\mathrm{CDH} 13$ as a novel susceptibility locus contributing to blood pressure determination in two European populations. Hum Mol Genet 2009; 18 : 2288-2296.

6 Wang Y, O'Connell JR, McArdle PF, Wade JB, Dorff SE, Shah SJ, Shi X, Pan L, Rampersaud E, Shen H, Kim JD, Subramanya AR, Steinle NI, Parsa A, Ober CC, Welling PA, Chakravarti A, Weder AB, Cooper RS, Mitchell BD, Shuldiner AR, Chang YP. Wholegenome association study identifies STK39 as a hypertension susceptibility gene. Proc Natl Acad Sci USA 2009; 106: 226-231.

7 Adeyemo A, Gerry N, Chen G, Herbert A, Doumatey A, Huang H, Zhou J, Lashley K, Chen Y, Christman M, Rotimi C. A genome-wide association study of hypertension and blood pressure in African Americans. PLoS Genet 2009; 5 : e1000564.

8 Cunnington MS, Kay C, Avery PJ, Mayosi BM, Koref MS, Keavney B. STK39 polymorphisms and blood pressure: an association study in British Caucasians and assessment of cis-acting influences on gene expression. BMC Med Genet 2009; 10: 135.

9 Chen LY, Zhao WH, Tian W, Guo J, Jiang F, Jin LJ, Sun YX, Chen KM, An LL, Li GD, Li Q, Li Y, Wu C, Zhao L, Wang WJ, Zheng GY, Li B, Li XQ, Hu J, Tian XL. STK39 is an independent risk factor for male hypertension in Han Chinese. Int J Cardiol 2010; doi.10.1016/j.ijcard.2010.09.007. 
10 Fava C, Danese E, Montagnana M, Sjögren M, Almgren P, Engström G, Nilsson P, Hedblad B, Guidi GC, Minuz P, Melander O. Serine/threonine kinase 39 is a candidate gene for primary hypertension especially in women: results from two cohort studies in Swedes. J Hypertens 2011; 29: 484-491.

11 Mancia G, De Backer G, Dominiczak A, Cifkova R, Fagard R, Germano G, Grassi G, Heagerty AM, Kjeldsen SE, Laurent S, Narkiewicz K, Ruilope L, Rynkiewicz A, Schmieder RE, Struijker Boudier HA, Zanchetti A, Vahanian A, Camm J, De Caterina R, Dean V, Dickstein K, Filippatos G, Funck-Brentano C, Hellemans I, Kristensen SD, McGregor K, Sechtem U, Silber S, Tendera M, Widimsky P, Zamorano JL, Erdine S, Kiowski W, Agabiti-Rosei E, Ambrosioni E, Lindholm LH, Manolis A, Nilsson PM, Redon J, Struijker-Boudier HA, Viigimaa M, Adamopoulos S, Bertomeu V, Clement D, Farsang C, Gaita D, Lip G, Mallion JM, Manolis AJ, O'Brien E, Ponikowski P, Ruschitzka F, Tamargo J, van Zwieten P, Waeber B, Williams B. Guidelines for the management of arterial hypertension: the Task Force for the Management of Arterial Hypertension of the European Society of Hypertension (ESH) and of the European Society of Cardiology (ESC). Eur Heart J 2007; 28: 1462-1536.

12 Chobanian AV, Bakris GL, Black HR, Cushman WC, Green LA, Izzo Jr JL, Jones DW, Materson BJ, Oparil S, Wright Jr JT, Roccella EJ. Seventh report of the Joint National Committee on Prevention, Detection, Evaluation, and Treatment of High Blood Pressure. Hypertension 2003; 42: 1206-1252.

13 Hiltunen TP, Suonsyrjä T, Hannila-Handelberg T, Paavonen KJ, Miettinen HE, Strandberg T, Tikkanen I, Tilvis R, Pentikäinen PJ, Virolainen J, Kontula K. Predictors of antihypertensive drug responses: initial data from a placebo-controlled, randomized, cross-over study with four antihypertensive drugs (the GENRES study). Am J Hypertens 2007; 20: 311-318.

14 Suonsyrjä T, Hannila-Handelberg T, Paavonen KJ, Miettinen HE, Donner K, Strandberg T, Tikkanen I, Tilvis R, Pentikäinen PJ, Kontula K, Hiltunen TP. Laboratory tests as predictors of the antihypertensive effects of amlodipine, bisoprolol, hydrochlorothiazide and losartan in men: results from the randomized, double-blind, crossover GENRES study. J Hypertens 2008; 26: 1250-1256.

15 Hannila-Handelberg T, Kontula K, Tikkanen I, Tikkanen T, Fyhrquist F, Helin K, Fodstad H, Piippo K, Miettinen HE, Virtamo J, Krusius T, Sarna S, Gautschi I, Schild L, Hiltunen TP. Common variants of the beta and gamma subunits of the epithelial sodium channel and their relation to plasma renin and aldosterone levels in essential hypertension. BMC Med Genet 2005; 6: 4.

$16 \mathrm{Ke}$ X, Collins A, Ye S. PIRA PCR designer for restriction analysis of single nucleotide polymorphisms. Bioinformatics 2001; 17: 838-839.

17 Faul F, Erdfelder E, Lang AG, Buchner A. G*Power 3: a flexible statistical power analysis program for the social, behavioral, and biomedical sciences. Behav Res Methods 2007; 39: 175-191.

18 Tomaschitz A, Pilz S, Ritz E, Obermayer-Pietsch B, Pieber TR. Aldosterone and arterial hypertension. Nat Rev Endocrinol 2010; 6: 83-93.

19 Richardson C, Alessi DR. The regulation of salt transport and blood pressure by the WNK-SPAK/OSR1 signalling pathway. J Cell Sci 2008; 121: 3293-3304.

20 Rhee MY, Yang SJ, Oh SW, Park Y, Kim CI, Park HK, Park SW, Park CY. Novel genetic variations associated with salt sensitivity in the Korean population. Hypertens Res 2011; 34: 606-611.

21 San-Cristobal P, Pacheco-Alvarez D, Richardson C, Ring AM, Vazquez N, Rafiqi FH, Chari D, Kahle KT, Leng Q, Bobadilla NA, Hebert SC, Alessi DR, Lifton RP, Gamba G. Angiotensin II signaling increases activity of the renal $\mathrm{Na}-\mathrm{Cl}$ cotransporter through a WNK4-SPAK-dependent pathway. Proc Natl Acad Sci USA 2009; 106: 4384-4389.

22 Talati G, Ohta A, Rai T, Sohara E, Naito S, Vandewalle A, Sasaki S, Uchida S. Effect of angiotensin II on the WNK-OSR1/SPAK-NCC phosphorylation cascade in cultured mpkDCT cells and in vivo mouse kidney. Biochem Biophys Res Commun 2010; 393: 844-848.

23 Rafiqi FH, Zuber AM, Glover M, Richardson C, Fleming S, Jovanovic S, Jovanovic A, O'Shaughnessy KM, Alessi DR. Role of the WNK-activated SPAK kinase in regulating blood pressure. EMBO Mol Med 2010; 2: 63-75.

24 Chiga M, Rai T, Yang SS, Ohta A, Takizawa T, Sasaki S, Uchida S. Dietary salt regulates the phosphorylation of OSR1/SPAK kinases and the sodium chloride cotransporter through aldosterone. Kidney Int 2008; 74: 1403-1409.

25 Duarte JD, Lobmeyer MT, Wang Z, Chapman AB, Gums JG, Langaee TY, Boerwinkle E, Turner ST, Johnson JA. Lack of association between polymorphisms in STK39, a putative thiazide response gene, and blood pressure response to hydrochlorothiazide. Pharmacogenet Genomics 2010; 20: 516-519.

Supplementary Information accompanies the paper on Hypertension Research website (http://www.nature.com/hr) 